\title{
PENGARUH MOTIVASI DAN LINGKUNGAN KERJA TERHADAP KINERJA KARYAWAN
}

\author{
Izzatin I’tamara \\ Universitas Negeri Surabaya \\ izzatin.17080574093@mhs.unesa.ac.id \\ Hafid Kholidi Hadi \\ Universitas Negeri Surabaya \\ hafidhadi@unesa.ac.id
}

\begin{abstract}
This research aims to analyze the impact of motivation and working environment on employee performance. The study was held in Perumda Air Minum Tirta Lestari in Tuban Regency. Perumda Air Minum Tirta Lestari is a company that provides clean water services. This study uses a quantitative approach with probability sampling techniques. The sample used was 96 employees. Statistics are multilinear regressions using SPSS. The results show that motivation significantly impacts employee performance while work environment variables have no significant effect on employee performance. Companies must increase employee motivation by increasing motivational factors to maintain performance.
\end{abstract}

Keywords: employee performance; motivation; work environment.

\section{PENDAHULUAN}

Sumber daya manusia adalah elemen dalam perusahaan di mana memiliki peran istimewa dalam mencapai keberhasilan suatu perusahaan (Susiawan \& Muhid, 2015). Menurut Sofyandi \& Garniwa (2007), manajemen sumber daya manusia dapat didefinisikan sebagai kebijakan untuk mewujudkan fungsi manajemen, termasuk penarikan, seleksi, pelatihan dan pengembangan, promosi, penurunan pangkat dan pemindahan, evaluasi kinerja, gaji, serta manajemen tenaga kerja dengan tujuan untuk meningkatkan keterlibatan produktif sumber daya manusia perusahaan demi menggapai misi perusahaan agar lebih efektif sesuai dengan penjelasan Mangkunegara (2016) bahwa mengendalikan sumber daya manusia agar menggapai target perusahaan meliputi perencanaan, koordinasi, implementasi, akuisisi, pengembangan, remunerasi, integrasi, pemeliharaan, dan pembagian kerja.

Kesuksesan suatu perusahaan ketika menciptakan sumber daya manusia yang memiliki kemampuan tinggi agar mencapai tujuan perusahaan tentunya tidak dapat terlepas dari faktor-faktor yang memengaruhi kinerja seseorang. Faktor motivasi berpengaruh bagi kinerja karyawan agar kualitas, kuantitas, serta produktifitas mereka tetap baik (Diamantidis \& Chatzoglou, 2019).

Dalam upaya menciptakan sumber daya manusia terbaik, perlu diikuti pengembangan karyawan yang tepat. Dengan motivasi kerja tinggi maka karyawan dapat bekerja tekun dalam menyelesaikan pekerjaannya. Motivasi merupakan bimbingan, arahan, dan penghargaan yang menginspirasi dan memunculkan ketertarikan untuk bekerja dengan cara yang diinginkan (Nabi et al., 2017). Motivasi adalah proses di mana seseorang perlu didorong untuk melakukan serangkaian aktivitas guna mencapai tujuan tertentu. Saat tujuan dicapai, maka dapat terpenuhi kebutuhan tersebut. Oleh karena itu, perusahaan perlu memerhatikan motivasi agar menerima kontribusi positif dari karyawan untuk mencapai tujuan perusahaan (Ratnasari \& Siregar, 2020).

Selain faktor motivasi kerja, lingkungan kerja menjadi suatu aspek yang berpengaruh dalam tercapainya kinerja karyawan. Lingkungan kerja dikatakan layak apabila karyawan dapat melakukan pekerjaan secara ideal, aman, sehat, dan nyaman (Al-Omari \& Okasheh, 2017). Untuk melaksanakan pekerjaan secara efektif dan efisien memerlukan lingkungan kerja yang kondusif (Priarso et al., 2019). Lingkungan kerja yang kondusif dan nyaman membuat karyawan dapat berkomunikasi dengan 
Izzatin I'tamara \& Hafid Kholidi Hadi. Pengaruh Motivasi dan Lingkungan Kerja terhadap Kinerja Karyawan

baik dan mampu bekerja sama, situasi ini membuat karyawan merasa puas dengan pekerjaan yang dilakukan (Andreani \& Petrik, 2016).

Menurut Mohamud et al. (2017), motivasi dapat berdampak positif pada kinerja karyawan di mana pekerja harus dimotivasi untuk memastikan mereka dapat memertahankan dan meningkatkan kinerja agar produktivitas dan efektivitas meningkat, pernyataan tersebut didukung Dharma (2017), Fei et al. (2018), Al-musadieq et al. (2018), dan Mohamud et al. (2017). Berlawanan dengan sejumlah penelitian tersebut, Sulastri et al. (2017) dan Karami et al. (2013) menjelaskan tidak ada pengaruh antara motivasi terhadap kinerja karyawan.

Lingkungan kerja berdampak signifikan pada kinerja karyawan, sehingga karyawan perlu meningkatkan ketertiban dan kebersihan ruang kerja, agar nyaman saat menyelesaikan pekerjaan (Simon \& Riyanto, 2020). Pernyataan tersebut didukung Mamesah et al (2016) dan Jayaweera (2015). Hal ini berlawanan dengan penelitian Pawirosumarto et al. (2016) dan Nurhuda et al. (2019) yang menjelaskan tidak ada pengaruh antara lingkungan kerja terhadap kinerja karyawan.

Perusahaan Umum Daerah (Perumda) Air Minum Tirta Lestari Kab. Tuban merupakan unit usaha milik daerah yang memberikan pelayanan distribusi air bersih kepada penduduk di Kabupaten Tuban. Dalam hal pelayanan air bersih kepada masyarakat, perusahaan dituntut untuk menjalankan tugasnya secara profesional dan efektif, sejalan dengan salah satu misi perusahaan yaitu memberikan pelayanan di bidang air minum secara mudah, cepat, tepat, terukur, dan terjangkau. Untuk menaikkan produktivitas karyawan, perlu dicapai dengan cara meningkatkan semangat kerja karyawan dan memerhatikan lingkungan kerja perusahaan, sehingga kinerja pegawai lebih efektif dan perusahaan dapat mencapai tujuan yang diharapkan (Perumda, 2020).

Hasil wawancara dengan Kepala Bagian Umum Perumda Air Minum Tirta Lestari Kabupaten Tuban, terdapat beberapa bentuk motivasi yang diberikan oleh atasan terhadap karyawan salah satunya adalah penghargaan, jika kinerja karyawan bagus perusahaan dapat memberikan penghargaan ataupun bonus bagi karyawan. Sehingga dapat membuat karyawan semakin termotivasi dalam menyelesaikan pekerjaan dan meningkatkan kinerja agar semakin baik.

Penelitian ini bertujuan untuk mengetahui bagaimana pengaruh motivasi dan lingkungan kerja terhadap kinerja karyawan.

\section{KAJIAN PUSTAKA DAN PENGEMBANGAN HIPOTESIS}

\section{Motivasi Kerja}

Menurut Wibowo (2016), motivasi kerja merupakan serangkaian proses yang membangkitkan, mengarahkan, dan menjaga perilaku manusia menuju pencapaian tujuan. Pawirosumarto \& Sarjana (2016) mengemukakan motivasi dapat diartikan sebagai dorongan dari dalam yang mendasari perilaku seseorang. Firmansyah et al. (2020) mengatakan motivasi sangat penting dalam perusahaan, semangat kerja tinggi akan menghasilkan produktivitas kerja tinggi pula untuk mencapai tujuan yang ditetapkan. Motivasi akan efektif jika karyawan mengetahui peran organisasinya dengan baik (Rita $e t$ al., 2018).

\section{Lingkungan Kerja}

Menurut Putri et al. (2018), lingkungan kerja adalah lingkungan fisik di mana pekerjaan karyawan memengaruhi kinerja mereka, keselamatan, dan kualitas kehidupan kerja. Parashakti et al. (2020) menjelaskan lingkungan kerja merupakan komponen penting bagi karyawan saat menyelesaikan pekerjaan. Kondisi lingkungan kerja dengan fasilitas lengkap, serta hubungan harmonis antar karyawan dapat menciptakan lingkungan kerja yang menyenangkan, jika lingkungan kerja buruk dan tidak dapat memenuhi kebutuhan maka dapat mengganggu konsentrasi dan keharmonisan antar karyawan serta memengaruhi efisiensi kerja (Sinambela, 2018). Lingkungan kerja berkualitas sangat penting bagi karyawan untuk bekerja secara efektif, dalam lingkungan kerja yang baik, karyawan 
akan merasa aman dan nyaman saat bekerja, sehingga membawa motivasi ekstra dalam meningkatkan efisiensi kerja (Agbozo et al., 2017).

\section{Kinerja}

Berdasarkan Mendis \& Weerakkody (2018), kinerja merupakan proses membangun kebersamaan pemahaman untuk mencapai tujuan dalam perusahaan. Kinerja dapat diartikan sebagai cara untuk melaksanakan tugas atau pekerjaan sesuai dengan uraian tugas yang ditentukan (Qatmeemalmarhoon et al., 2017). Menurut Riupassa (2018), kinerja dapat dicapai apabila karyawan memiliki motivasi kerja.

\section{Hubungan antar Variabel}

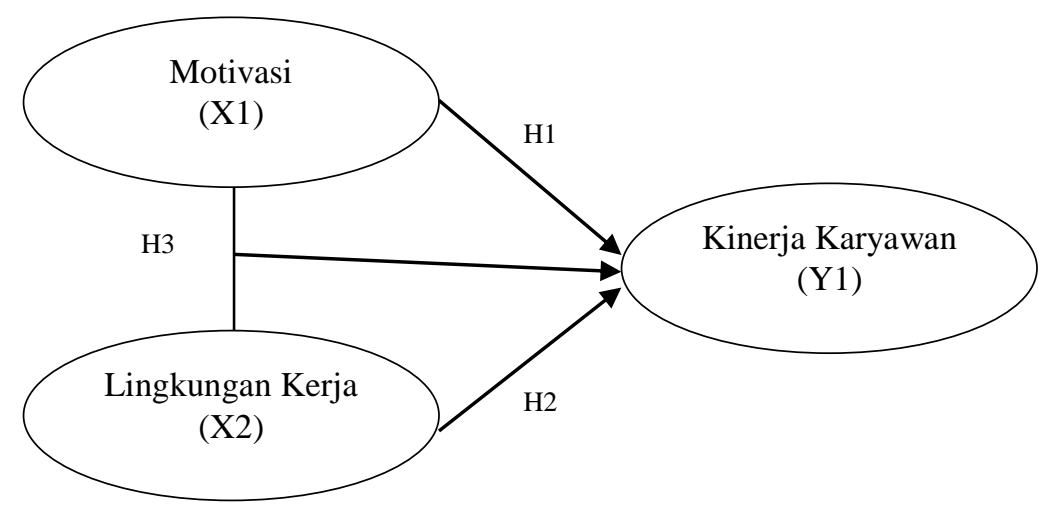

Gambar 1. KERANGKA KONSEPTUAL

Fei et al. (2018) dan Mohamud et al. (2017) menyatakan motivasi kerja berdampak positif dan signifikan pada kinerja karyawan. Dharma (2017) memaparkan motivasi karyawan perlu ditingkatkan dalam kesadaran karyawan, pengembangan karir, dan kesejahteraan sehingga karyawan tetap bersemangat, termotivasi, dan dapat meningkatkan kinerja di masa depan.

H1: Motivasi berpengaruh positif pada kinerja karyawan.

Simon \& Riyanto (2020) menemukan adanya pengaruh positif dan signifikan antara lingkungan kerja terhadap kinerja karyawan. Mamesah et al. (2016) menunjukkan peningkatan dan penurunan kinerja dipengaruhi oleh aspek lingkungkan seperti penerangan, suhu udara, suara bising, keamanan kerja, hubungan dengan rekan kerja atau atasan.

H2: Lingkungan kerja berpengaruh positif pada kinerja karyawan.

Riyanto et al. (2017) mengemukakan pengaruh yang signifikan antara motivasi dan lingkungan kerja terhadap kinerja karyawan. Turnip (2020) menjelaskan secara bersama-sama motivasi dan lingkungan kerja berpengaruh signifikan terhadap kinerja karyawan bahwa semakin tinggi dan semakin baik lingkungan kerja akan berdampak pada semakin baik kinerja karyawan, memotivasi karyawan secara individual dan menciptakan lingkungan kerja yang baik serta menyenangkan sehingga memberikan daya tarik bagi karyawan untuk meningkatkan kinerja.

H3: Motivasi dan lingkungan diduga memiliki pengaruh simultan pada kinerja karyawan. 
Izzatin I'tamara \& Hafid Kholidi Hadi. Pengaruh Motivasi dan Lingkungan Kerja terhadap Kinerja Karyawan

\section{METODE PENELITIAN}

Penelitian ini dilakukan di Perumda Air Minum Tirta Lestari Kab. Tuban, serts menerapkan metode kuantitatif dengan teknik pengambilan sampel menggunakan proportionate stratified random sampling dan sampel penelitian berjumlah 96 dari 125 populasi yang meliputi bagian administrasi umum dan kepegawaian, bagian keuangan, bagian hubungan langganan, bagian perencanaan dan pengawasan teknik, bagian produksi, transmisi, dan distribusi, serta bagian cabang wilayah. Skala pengukuran pada penelitian ini menggunakan skala Likert lima skala. Uji validitas yang digunakan adalah uji reliabilitas untuk melihat kelayakan instrumen penelitian pada kinerja karyawan Perumda Air Minum Tirta Lestari Kabupaten Tuban dan menganalisis data menggunakan uji asumsi klasik. Sementara analisis statistik memanfaatkan analisis statistik deskriptif serta analisis regresi linier berganda dengan software SPSS.

\section{HASIL DAN PEMBAHASAN}

\section{Uji Asumsi Klasik}

Uji asumsi klasik yaitu uji normalitas, multikolinieritas, hererokedastisitas, serta autokorelasi. Uji normalitas memanfaatkan uji One Sample Kolmogorov-Smirnov (K-S) yang menyatakan tingkat signifikansi sebesar 0,200 berarti tingkat signifikansi lebih dari 0,05. Artinya mampu diinterprestasikan data berdistribusi normal. Uji multikolinieritas di mana dua variabel terikat memiliki nilai tolerance lebih dari 0,01 yaitu 0,930 dan skor Variance Factor (VIF) menunjukkan kurang dari 10 yaitu 1,075. Artinya tidak terjadi multikolinieritas dalam kedua variabel. Uji heterokedastisitas melalui scatterplot dapat dilihat pada gambar 2. Di mana titik pada sumbu Y menyebar luas di atas serta di bawah nol dan tidak terbentuk pola tertentu. Artinya heterokedastisitas tidak terdapat pada model regresi ini. Uji autokorelasi didapatkan dari nilai Durbin-watson sebesar 2,080 lebih besar dari nilai du yaitu 1,7103 serta lebih kecil dari nilai 4-du yakni 2,2897. Artinya, tidak terdapat autokorelasi di model regresi ini.

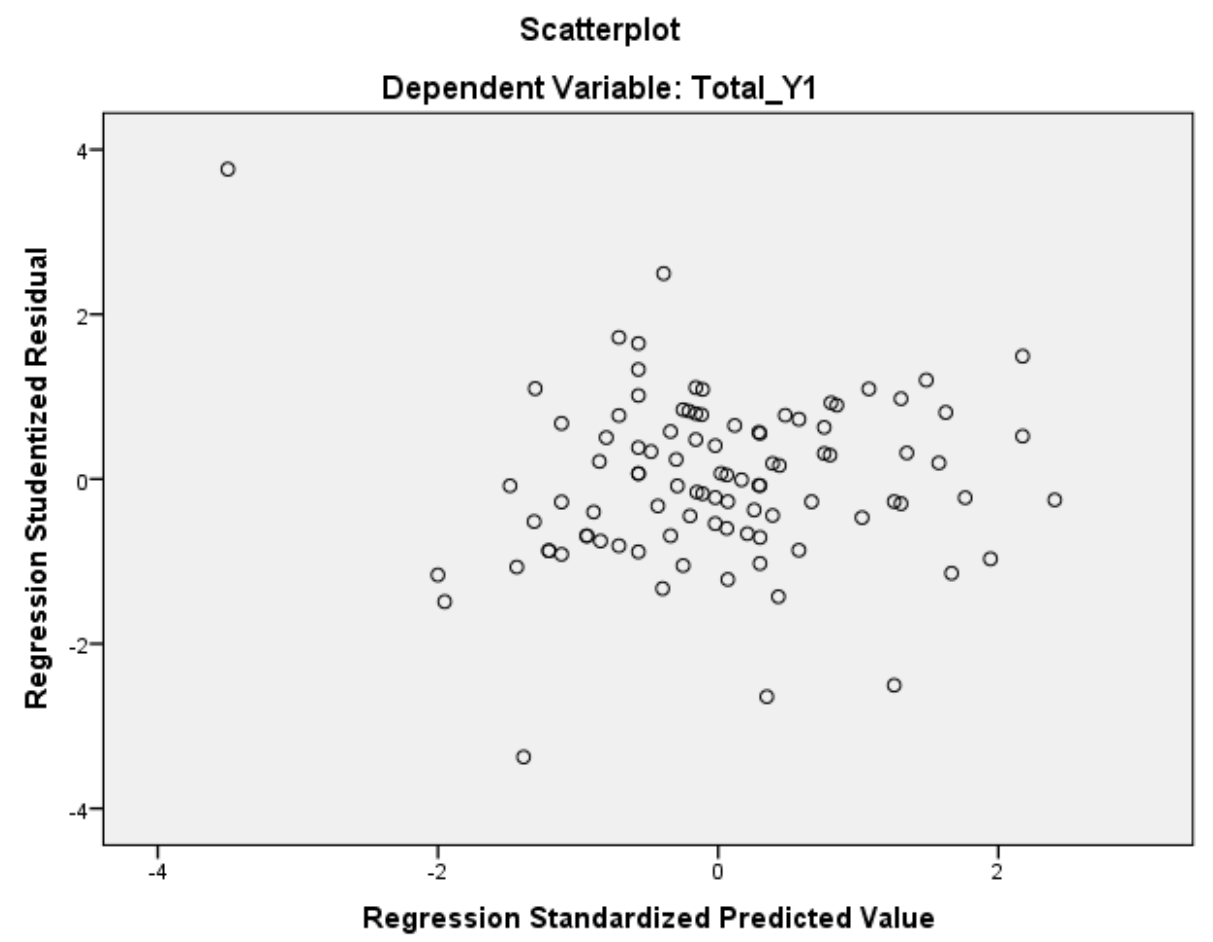

Sumber: Output SPSS (2021)

Gambar 2. SCATTERPLOT 


\section{Uji Regresi Linier Berganda}

Tabel 1 menunujukkan nilai $\alpha$ positif 21.116, artinya apabila variabel independen tidak memiliki nilai atau 0 maka nilai variabel dependen yaitu 21.116. Koefisien variabel motivasi pada kinerja adalah positif dan memiliki nilai 0,384 . Koefisien variabel lingkungan kerja pada kinerja adalah positif dan memiliki nilai 0,151 .

Tabel 1.

HASIL REGRESI LINIER BERGANDA

\begin{tabular}{|c|c|c|c|c|c|c|}
\hline \multirow{2}{*}{\multicolumn{2}{|c|}{ Model }} & \multicolumn{2}{|c|}{ Unstandardized Coefficients } & \multirow{2}{*}{$\begin{array}{c}\text { Standardized Coefficients } \\
\text { Beta }\end{array}$} & \multirow[t]{2}{*}{$\mathbf{t}$} & \multirow[t]{2}{*}{ Sig. } \\
\hline & & B & Std. Error & & & \\
\hline 1 & (Constant) & 21.116 & 4.878 & \multirow{3}{*}{$\begin{array}{l}.426 \\
.115\end{array}$} & 4.329 & .000 \\
\hline & Motivasi & .384 & .086 & & 4.487 & .000 \\
\hline & Lingkungan Kerja & .151 & .125 & & 1.211 & .229 \\
\hline
\end{tabular}

Sumber: Output SPSS (2021, data diolah)

Tabel 2.

HASIL UJI F

\begin{tabular}{|c|c|c|c|c|c|c|}
\hline \multicolumn{2}{|c|}{ Model } & Sum of Squares & $d f$ & Mean Square & $F$ & Sig. \\
\hline \multicolumn{2}{|c|}{1 Regression( } & 267.151 & 2 & 133.575 & 13.148 & $.000^{\mathrm{b}}$ \\
\hline & Residual & 944.849 & 93 & 10.160 & & \\
\hline & Total & 1212.000 & 95 & & & \\
\hline
\end{tabular}

Sumber : Output SPSS (2021, data diolah)

\section{Uji Signifikan Simultan (Uji F)}

Tabel 2 menunjukkan nilai signifikansi adalah 0,000 kurang dari 0,05 serta $\mathrm{F}$ hitung 13.148 lebih dari $\mathrm{F}$ tabel 9,34. Sehingga, variabel dependen dipengaruhi oleh semua variabel independen secara signifikan.

\section{Uji Signifikan Simultan (Uji t)}

Berasarkan Tabel 1, nilai signifikansi variabel motivasi sebanyak 0,000 kurang dari 0,05 mengindikasikan X1 berpengaruh signifikan pada kinerja karyawan Perumda Air Minum Tirta Lestari Kabupaten Tuban. Sedangkan nilai signifikansi pada variabel lingkungan kerja 0,229 dan lebih besar dari 0,05 artinya X2 tidak berpengaruh signifikan pada kinerja karyawan Perumda Air Minum Tirta Lestari Kabupaten Tuban.

\section{Koefisien Determinasi (R2)}

Dalam koefisien determinasi (R2) memiliki peranan untuk mengetahui kemampuan model dalam menjelaskan variabel bebas. Pada koefisien determinasi nilai yang dimiliki yaitu nol dan satu.

Tabel 3.

HASIL KOEFISIEN DETERMINASI

\begin{tabular}{lrrrr}
\hline Model & $\boldsymbol{R}$ & $\boldsymbol{R}$ Square & Adjusted $\boldsymbol{R}$ Square & Std. Error of the Estimate \\
\hline 1 & $.469^{\mathrm{a}}$ & .220 & .204 & 3.18742 \\
\hline
\end{tabular}

Sumber: Output SPSS

Tabel 3 menunjukkan Adjusted $R$ Square memiliki nilai 0,204. Artinya sebesar 20,4\% kinerja karyawan diakibatkan oleh motivasi dan lingkungan kerja, sedangkan sebesar 79,6\% diakibatkan aspek lain yang tidak dikaji seperti variabel budaya organisasi, gaya kepemimpinan, displin kerja, dan stres kerja yang mampu menggambarkan kinerja karyawan selaku variabel tambahan. Artinya variabel motivasi bersama lingkungan kerja memiliki pengaruh pada kinerja karyawan di Perumda Air Minum Tirta Lestari Kabupaten Tuban. 
Izzatin I'tamara \& Hafid Kholidi Hadi. Pengaruh Motivasi dan Lingkungan Kerja terhadap Kinerja Karyawan

\section{Pengaruh Motivasi terhadap Kinerja Karyawan}

Penelitian ini mengungkapkan faktor motivasi mempunyai dampak signifikan pada kinerja karyawan, kondisi ini dibuktikan dengan variabel motivasi kerja pada kinerja karyawan tergolong baik, di mana karyawan Perumda Air Minum Tirta Lestari Kabupaten Tuban sebesar mayoritas merasa gaji yang diberikan cukup untuk memenuhi kebutuhan fisiologis, karyawan merasa aman dan nyaman ketika bekerja, merasa dihargai atas hasil kerja keras mereka, karyawan juga diberikan penghargaan serta pelatihan untuk menunjang keterampilan karyawan, selain itu karyawan juga mendapatkan tunjangan hari tua, asuransi keselamatan kerja.

Hal ini didukung Fei et al. (2018) yang mengemukakan motivasi kerja berdampak positif serta signifikan pada kinerja karyawan perusahaan jasa, bahwa semakin karyawan termotivasi, semakin tinggi pula produktivitas karyawan. Kondisi ini juga didukung Al-musadieq et al. (2018) motivasi berpengaruh positif dan signifikan terhadap kinerja karyawan di sektor konstruksi yang menjelaskan kinerja sumber daya manusia dipengaruhi oleh aspek-aspek manajemen sumber daya manusia berikut, motivasi kerja meliputi sistem penghargaan, perasaan sosial, dan aktualisasi diri. Dharma (2017) menyatakan motivasi memiliki pengaruh signifikan terhadap kinerja karyawan, di mana kesadaran karyawan, pengembangan karir, dan kesejahteraan karyawan dapat meningkatkan kualitas kinerja.

\section{Pengaruh Lingkungan Kerja terhadap Kinerja Karyawan}

Lingkungan kerja tidak berdampak pada kinerja karyawan. Berdasarkan wawancara dengan Kepala Bagian Umum Perumda Air Minum Tirta Lestari Kabupaten Tuban mengatakan bahwa lingkungan kerja dalam perusahaan masuk dalam kategori yang baik, tersedianya fasilitas yang lengkap, terdapat area untuk berolahraga, musholla untuk beribadah, tempat parkir yang luas, lingkungan yang bersih, dan lain sebagainya. Selain itu, hubungan karyawan dengan rekan kerja juga baik di mana antar karyawan mampu bersama-sama menghargai serta menyegani satu sama lain. Hal ini diartikan bahwa lingkungan kerja tidak memengaruhi kinerja karyawan Perumda Air Minum Tirta Lestari Kabupaten Tuban. Adanya angka tidak signifikan ini mengindikasikan bahwa semakin baik atau tidak lingkungan kerja pada perusahaan, maka tidak memengaruhi kinerja karyawan.

Penelitian ini mendukung hasil penelitian yang menjelaskan Pawirosumarto et al. (2016) menjelaskan lingkungan kerja tidak berdampak positif dan signifikan pada kinerja karyawan, lingkungan kerja tidak selalu menjadi hal penting untuk meningkatkan kinerja karyawan. Nurhuda et al. (2019) mengemukakan lingkungan kerja tidak berpengaruh signifikan terhadap kinerja karyawan, bahwa semakin baik lingkungan kerja tidak memengaruhi kinerja pegawai.

\section{KESIMPULAN}

Hasil penelitian menyimpulkan bahwa motivasi berpengaruh signifikan pada kinerja karyawan Perumda Air Minum Tirta Lestari Kabupaten Tuban. Implikasinya bagi perusahaan diharapkan dapat meningkatkan motivasi karyawan, karena semakin tinggi motivasi yang diberikan akan berdampak pada semakin baik kinerja karyawan. Untuk memertahankan kinerja karyawan perusahaan dapat meningkatkan faktor-faktor motivasi seperti kebutuhan fisiologis, aktualisasi diri, meningkatkan kepuasaan kerja, gaji dan tunjangan sesuai dengan status karyawan, pemberian reward atau prestasi, menjalin hubungan baik dengan rekan kerja, beban kerja sesuai kemampuan sebagai usaha menciptakan kinerja karyawan yang lebih baik dari sebelumnya. Sementara lingkungan kerja tidak memiliki dampak signifikan pada kinerja karyawan. Hasil tersebut mencerminkan bahwa kondisi lingkungan kerja Perumda Air Minum Tirta Lestari Kabupaten Tuban belum mencapai kondisi yang ideal, sehingga tidak memberikan pengaruh yang signifikan terhadap kinerja karyawan.

Hasil penelitian ini dimohon mampu menjadi bahan pertimbangan pihak perusahaan dalam bentuk peningkatan kinerja karyawan. Pelatihan karyawan dan penghargaan pada karyawan tentunya memberikan hasil yang baik bagi perusahaan di mana karyawan akan bekerja lebih keras, dengan kata lain kinerja karyawan semakin meningkat. Perumda Air Minum Tirta Lestari Kabupaten Tuban disarankan untuk mengubah atau menyesuaikan suasana dan kondisi lingkungan kerja yang dibutuhkan karyawan untuk mencapai hasil yang lebih baik. Disisi lain, untuk penelitian berikutnya 
dapat melibatkan variabel tambahan yang mampu memengaruhi kinerja karyawan seperti variabel budaya organisasi, gaya kepemimpinan, disiplin kerja, dan stres kerja.

\section{DAFTAR PUSTAKA}

Agbozo, G., Owusu, I., Hoedoafia, M., \& Atakorah, Y. (2017). The Effect of Work Environment on Job Satisfaction: Evidence from the Banking Sector in Ghana. Journal of Human Resource Management, 5(1), 12-18. https://doi.org/10.11648/j.jhrm.20170501.12

Al-Musadieq, M., Nurjannah, Raharjo, K., Solimun, \& Fernandes, A. A. R. (2018). The Mediating Effect of Work Motivation on The Influence of Job Design and Organizational Culture Against HR Performance. Journal of Management Development, 37(6), 452-469. https://doi.org/10.1108/JMD-07-2017-0239

Al-Omari, K., \& Okasheh, H. (2017). The Influence of Work Environment on Job Performance: a case Study of Engineering Company in Jordan. International Journal of Applied Engineering Research, 12(24), 15544-15550.

Andreani, F., \& Petrik, A. (2016). The Effect of Transformational Leadership and Job Satisfaction on Employee Performance. Universal Journal of Management, 18(1), 25-32. https://doi.org/10.9744/jmk.18.1.25-32

Dharma, Y. (2017). The Effect of Work Motivation on the Employee Performance with Organization Citizenship Behavior as Intervening Variable at Bank Aceh Syariah. Emerald Reach Proceedings Series, 1, 7-12. https://doi.org/10.1108/978-1-78756-793-1-00065

Diamantidis, A. D., \& Chatzoglou, P. (2019). Factors Affecting Employee Performance: an Empirical Approach. International Journal of Productivity and Performance Management, 68(1), 171193. https://doi.org/10.1108/IJPPM-01-2018-0012

Fei, T., Hotlan, I., Sc, M., Bisnis, P. M., Manajemen, P. S., Petra, U. K., \& Siwalankerto, J. (2018). Pengaruh Kepuasan Kerja terhadap Kinerja Karyawan melalui Motivasi Kerja pada CV. Union Event Planner. Agora, 6(1), 1-6.

Firmansyah, A., Maupa, H., Taba, I., \& Hardiyono, H. (2020). The Effect of Work Motivation, Work Environment, and Work Discipline on Employees' Performance Of Samsat Office, Makassar. Hasanuddin Journal of Business Strategy, 2(2), 72-78. https://doi.org/10.26487/hjbs.v2i2.336

Jayaweera, T. (2015). Impact of Work Environmental Factors on Job Performance, Mediating Role of Work Motivation: A Study of Hotel Sector in England. International Journal of Business and Management, 10(3), 271-278. https://doi.org/10.5539/ijbm.v10n3p271

Karami, A., Dolatabadi, H. R., \& Rajaeepour, D. S. (2013). Analyzing the Effectiveness of Reward Management System on Employee Performance through the Mediating Role of Employee Motivation Case Study: Isfahan Regional Electric Company. International Journal of Academic Research in Business and Social Sciences, 3(9), 327-338. https://doi.org/10.6007/ijarbss/v3$\mathrm{i} 9 / 215$

Mamesah, A. M. C., Kawet, L., \& Lengkong, V. P. K. (2016). Influence of Environmental Work, Work Dicipline, and Loyalty to Work on the Performance Employees at LPP RRI Mando. Jurnal Emba, 4(3), 600-611.

Mangkunegara, A. A. A. P. (2016). Manajemen Sumber Daya Manusia Perusahaan. Bandung: PT. Remaja Rosdakarya. 
Izzatin I'tamara \& Hafid Kholidi Hadi. Pengaruh Motivasi dan Lingkungan Kerja terhadap Kinerja Karyawan

Mendis, M. D. V. S., \& Weerakkody, W. A. S. (2018). The Impact of Work Life Balance on Employee Performance with Reference to Telecommunication Industry in Sri Lanka: a Mediation Model. Kelaniya Journal of Human Resource Management, 12(1), 72-100. https://doi.org/10.4038/kjhrm.v12i1.42

Mohamud, S. A., Ibrahim, A. A., \& Hussein, J. M. (2017). The Effect of Motivation on Employee Performance: Case Study in Hormuud Company in Mogadishu Somalia. International Journal of Development Research, 7(11), 17009-17016. http://www.journalijdr.com

Nabi, N., Islam, M., Dip, T. M., \& Hossain, A. Al. (2017). Impact of Motivation on Employee Performance: a case Study of Karmasangsthan Bank Limited, Bangladesh. Arabian Journal of Business and Management Review, 7(1). https://doi.org/10.4172/2223-5833.1000146

Nurhuda, A., Purnamasari, W., Irawan, N., Nurhidayati, F., Mahmudah, S., Anshori, M., Ngibad, K., Fathoni Rodli, A., Hidayatullah, S., \& Yahya, D. (2019). Effect of Transformational Leadership Style, Work-Discipline, Work Environment on Employee Motivation and Performance. Journal of Physics: Conference Series, 1175(1). https://doi.org/10.1088/1742-6596/1175/1/012288

Parashakti, R. D., Fahlevi, M., Ekhsan, M., \& Hadinata, A. (2020). The Influence of Work Environment and Competence on Motivation and Its Impact on Employee Performance in Health Sector. Advances in Economics, Business and Management Research, 135, 259-267. https://doi.org/10.2991/aebmr.k.200410.040

Pawirosumarto, S., \& Sarjana, P. K. (2016). Factors Affecting Employee Performance of PT . Kiyokuni Indonesia. International Journal of Law and Management, 59(4), 602-614. https://doi.org/10.1108/IJLMA-03-2016-0031

Pawirosumarto, S., Sarjana, P. K., \& Gunawan, R. (2016). The Effect of Work Environment, Leadership Style, and Organizational Culture towards Job Satisfaction and Its Implicartion towards Employee Performance in Parador Hotels and Resort, Indonesia. International Jurnal of Law and Management, 59(6), 1337-1358. https://doi.org/10.1108/JJLMA-10-2016-0085

Perumda. (2020). Sejarah Perusahaan. (http://www.perumdaairminumtuban.co.id. diakses pada 23 Maret 2021)

Priarso, M. T., Diatmono, P., \& Mariam, S. (2019). The Effect of Transformational Leadership Style, Work Motivation, and Work Environment on Employee Performance That in Mediation By Job Satisfaction Variables in Pt. Gynura Consulindo. Business and Entrepreneurial Review, 18(2), 165. https://doi.org/10.25105/ber.v18i2.5334

Putri, D. O., Triatmanto, B., \& Setiyadi, S. (2018). The Effect of Occupational Health and Safety, Work Environment and Discipline on Employee Performance in a Consumer Goods Company. IOP Conference Series: Materials Science and Engineering, 337(1). https://doi.org/10.1088/1757-899X/337/1/012036

Qatmeemalmarhoon, A., Mohdnoor, K., Abdalla, M., \& Musbah, A. (2017). Effect of Motivation on Employees' Performance and Employees' Commitment. International Journal of Management and Applied Science, 3(9), 2394-7926. http://iraj.in

Ratnasari, S. L., \& Siregar, D. (2020). Bagaimana Upaya Meningkatkan Kinerja Guru? Jurnal Bening Prodi Manajemen Universitas Riau Kepulauan Batam, 7(1), 119-125.

Rita, M., Randa Payangan, O., Rante, Y., Tuhumena, R., \& Erari, A. (2018). Moderating Effect of Organizational Citizenship Behavior on The Effect of Organizational Commitment, Transformational Leadership and Work Motivation on Employee Performance. International 
Journal of Law and Management, 60(4), 953-964. https://doi.org/10.1108/IJLMA-03-20170026

Riupassa, E. (2018). The Influence of Organizational Culture and Work Motivation. RJOAS, 9(81), September 2018, 9(81), 88-95.

Riyanto, S., Sutrisno, A., \& Ali, H. (2017). The Impact of Working Motivation and Working Environment on Employees Performance. International Review of Management and Marketing, 7(3), 342-348. https://www.econjournals.com/index.php/irmm/article/view/5269/pdf

Simon, O., \& Riyanto, S. (2020). The Effect of Compensation, and Work Environment on Employee Performance. International Journal of Scientific and Technology Research, 9(6), 59-61.

Sinambela, L. P. (2018). Manajemen Sumber Daya Manusia (Suryani \&). Jakarta: Bumi Aksara.

Sofyandi, H., \& Garniwa, I. (2007). Perilaku Organisasi. Yogyakarta: Graha Ilmu.

Sulastri, E., Ghalib, S., \& Taharuddin. (2017). Pengaruh Budaya Organisasi , Motivasi , Dan Kepuasan Kerja Terhadap Kinerja Karyawan PT . PLN (Persero) Wilayah Kalimantan Selatan dan Kalimantan Tengah Area Kuala Kapuas. Jurnal Bisnis Dan Pembangunan, 6(1), 26-35.

Susiawan, S., \& Muhid, A. (2015). Kepemimpinan Transformasional, Kepuasan Kerja dan Komitmen Organisasi. Jurnal Psikologi Indonesia, 4(03), 304-313.

Turnip, W. J. (2020). Effect of Motivation and Work Environment on Employee Performance of PT . XYZ. Enrichment: Journal of Management, 10(2), 39-43. www.enrichment.iocspublisher.org

Wibowo. (2016). Manajemen Kinerja. Jakarta: PT. Rajagrafindo Persada. 